\title{
Mutations in TP53 increase the risk of SOX2 copy number alterations and silencing of TP53 reduces SOX2 expression in non-small cell lung cancer
}

Johanna Samulin Erdem, Vidar Skaug ${ }^{1}$, Per Bakke², Amund Gulsvik², Aage Haugen ${ }^{1}$ and Shanbeh Zienolddiny ${ }^{1 *}$

\begin{abstract}
Background: Amplifications of the transcription factor, SRY (sex determining region Y)-box 2 (SOX2), are common in non-small cell lung cancer (NSCLC). SOX2 signaling is important in maintaining the stem cell-like phenotype of cancer cells and contributes to the pathogenesis of lung cancer. TP53 is known to inhibit gene amplifications and to repress many stem cell-associated genes following DNA damage. The aim of this study was to investigate if TP53 mutational status affected SOX2 copy number variation and gene expression in early-stage NSCLC patients; moreover, to assess if TP53 regulates SOX2 expression in human lung cancer cells.

Methods: 258 early-stage lung cancer patients were included in the study. Exons 4-9 in the TP53 gene were sequenced for mutations in tumor tissues. SOX2 copy number as well as TP53 and SOX2 gene expression were analyzed in tumor and in adjacent non-tumorous tissues by qPCR. TP53 and SOX2 were silenced using gene-specific siRNAs in human lung adenocarcinoma A427 cells, and the expression of TP53, SOX2 and subset of selected miRNAs was analyzed by qPCR. The odds ratios (ORs) for associations between copy number variation and lung cancer were estimated by conditional logistic regression, and the correlation between gene status and clinicopathological characteristics was assessed by Chi-square or Fisher's exact test. Gene expression data was analyzed using nonparametric Mann-Whitney test.
\end{abstract}

Results: TP53 mutations were associated with an increased risk of acquiring a SOX2 copy number alteration $(\mathrm{OR}=2.08,95 \% \mathrm{Cl}: 1.14-3.79, p=0.017)$, which was more frequently occurring in tumor tissues (34\%) than in adjacent non-tumorous tissues (3\%). Moreover, SOX2 and TP53 expression levels were strongly correlated in tumor tissues. In vitro studies showed that a reduction in TP53 was associated with decreased SOX2 expression in A427 cells. Furthermore, TP53 knockdown reduced the miRNA hsa-miR-145, which has previously been shown to regulate SOX2 expression.

Conclusions: TP53 signaling may be important in the regulation of SOX2 copy number and expression in NSCLC tumors, and the miRNA hsa-miR-145-5p may be one potential driver. This prompts for further studies on the mechanisms behind the TP53-induced regulation of SOX2 expression and the possible importance of hsa-miR-145 in lung cancer.

Keywords: SRY (sex determining region Y)-box 2, NSCLC, TP53 mutation, Copy number alteration, Hsa-miR-14

\footnotetext{
* Correspondence: shan.zienolddiny@stami.no

${ }^{1}$ Department of Biological and Chemical Work Environment, National

Institute of Occupational Health, PO Box 8149 Dep, N-0033 Oslo, Norway

Full list of author information is available at the end of the article
}

\section{Ciomed Central}

(c) 2016 Samulin Erdem et al. Open Access This article is distributed under the terms of the Creative Commons Attribution 4.0 International License (http://creativecommons.org/licenses/by/4.0/), which permits unrestricted use, distribution, and reproduction in any medium, provided you give appropriate credit to the original author(s) and the source, provide a link to the Creative Commons license, and indicate if changes were made. The Creative Commons Public Domain Dedication waiver (http://creativecommons.org/publicdomain/zero/1.0/) applies to the data made available in this article, unless otherwise stated. 


\section{Background}

Lung cancer is the most frequent cause of cancerrelated mortality worldwide, leading to an estimated 1.4 million deaths in 2010 [1]. Smoking, occupational and environmental exposures to chemicals are major causes of lung cancer. Lung cancer constitutes a heterogeneous disease in regard to clinical presentation, pathological features and biological behavior. The majority of cases are non-small cell lung carcinomas (NSCLC), which comprises adenocarcinoma, squamous cell carcinoma and large cell carcinoma. The genomic alterations occurring in lung carcinomas are very complex [2-5]. However, alterations in the TP53 gene are among the most significant genetic events in lung cancers [6], often occurring as a response to DNA damage caused by exposure to a variety of genotoxic agents such as polycyclic aromatic hydrocarbons (PAHs) [7]. Mutations in the TP53 gene increase the risk for chromosomal rearrangements, such as copy number alterations, which are involved in the development and progression of many human malignancies including lung cancer [8]. Amplifications or deletions in the fragile sites harboring important transcription factors may further advance the process of carcinogenesis [9].

The transcription factor SRY (sex determining region $\mathrm{Y}$ )-box 2 , encoded by the $S O X 2$ gene located at the 3q25-27 region, is often altered in NSCLC [10, 11]. SOX2 has a crucial role in maintaining the stem cell-like phenotype in cancer cells $[12,13]$ and contributes to the pathogenesis of lung cancer by controlling cell proliferation and malignant transformation [11]. In lung cancer, SOX2 gene amplification and consequent increased expression occur most frequently in squamous cell carcinoma $[14,15]$ and to a lesser extent in adenocarcinoma $[14,16]$. Interestingly, TP53 has been reported to regulate SOX2 expression in embryonic stem cells [17] and recently also in the H1299 lung carcinoma cell line [18]. miRNAs are important mediators of TP53signaling and in embryonic stem cells TP53 represses SOX2 expression through the activation of hsa-miR-145 [19-21]. This is of interest as a recent study showed that low levels of hsa-miR-145 are associated with unfavorable prognosis in NSCLC [22].

Given the crucial role of TP53 and SOX2 in lung cancer and their known association in stem cell development, we hypothesize that TP53 may have a regulatory effect on SOX2 in lung cancer. Thus, effects of TP53 mutations on SOX2 copy number alterations were studied in lung cancer tumors and correlation between the gene expression levels investigated. Furthermore, effects of TP53 silencing on SOX2 mRNA levels were evaluated and the possibility of miRNAs as downstream regulators was assessed.

\section{Methods}

Cases

Early-stage lung cancer patients $(n=258)$ were Caucasians of Norwegian origin admitted to Haukeland University Hospital in Bergen between 1988 and 1994, for primary surgery. The patients were enrolled in the study, whenever practically feasible, and informed written consent covering analysis of molecular and genetic markers was signed by the patients prior to surgery. The subjects included in this manuscript are a subgroup recruited into the project "lung cancer genetics" at our institute. The project has been approved by the Regional Committee for Medical and Health Research Ethics in South Norway in accordance with the WMA Declaration of Helsinki. The ethical approval covered access to the NSCLC databank. The characteristics of the patients included in the study are summarized in Table 1. Samples of adjacent nontumorous lung tissue, confirmed by histology, were cut from the lobectomi specimens at the time of surgery. Tumor histology was confirmed by an experienced pathologist and samples containing $\geq 80 \%$ of tumor cells were analyzed in the study. After resection tumor

Table 1 Characteristics of patients $(n=258)$

\begin{tabular}{ll}
\hline Age & \\
(Mean \pm SD) & $63.9 \pm 10.1$ \\
(Median, min-max) & $66(25-82)$ \\
Gender (male: female) & $183 / 74$ \\
Smokers/Non-smokers & $222 / 22$ \\
No cigarettes per day & \\
(Mean \pm SD) & $15.3 \pm 7.9$ \\
(Median, min-max) & $14(2-50)$ \\
Total years of smoking & \\
(Mean \pm SD) & $41.3 \pm 11.6$ \\
(Median, min-max) & $43(2-69)$ \\
Total pack-years* & \\
(Mean \pm SD) & $31.6 \pm 18.2$ \\
(Median, min-max) & $28(1-113)$ \\
Histology & \\
Adenocarcinoma & $118(45.7 \%)$ \\
Squamous cell carcinoma & $103(39.9 \%)$ \\
Large cell carcinoma & $36(13.9 \%)$ \\
Others & 1 \\
PAH-DNA adducts ${ }^{\dagger}$ & \\
(Mean \pm SD) & $12.3 \pm 8.9$ \\
(Median, min-max) & 10 (1-46) \\
TP53 mutated/WT & \\
\hline Pak-years indictes the number & \\
\hline
\end{tabular}

"Pack-years indicates the number of cigarettes smoked per day $\mathrm{x}$ number of years smoked/20. ${ }^{\dagger}$ PAH-DNA adducts per $10^{8}$ nucleotides 
and non-tumorous tissues were snap-frozen in liquid nitrogen and kept at $-80{ }^{\circ} \mathrm{C}$ until further processing.

\section{Copy number analyses by quantitative PCR}

DNA was extracted from frozen lung tissue samples using standard proteinase $\mathrm{K}$ digestion followed by phenol-chloroform extraction and ethanol precipitation. Control DNA was isolated from blood samples by Flexigene DNA kit (Qiagen, Hilden, Germany). SOX2 copy number alterations were evaluated by quantitative real-time PCR (qPCR) using SYBR Green I technology on an ABI PRISM ${ }^{\circ} 7900$ HT Fast PCR System (Applied Biosystems, Thermo Scientific, Waltham, MA, USA), as described elsewhere [23, 24]. The multicopy gene FTH1 was used as reference gene. Primer sequences were: SOX2 forward primer, 5'-GCTCTTGGCTCCATGGGT TC-3', reverse primer, 5'-GCTGATCATGTCCCGGAGG T-3', FTH1 forward primer, 5'-GATGATGTGGCTTTG AAGAACTTTGCCA-3', reverse primer, 5'-CACCTCG TTGGTTCTGCAGCTTCATCA-3'. Primer specificity was determined by melting point analysis. qPCR was performed using $20 \mathrm{ng}$ template DNA in a total volume of $10 \mu \mathrm{L}$ containing PerfeCTa SYBR Green FastMix, ROX (QuantaBioSciences, Gaithersburg, MD, USA). Cycling conditions were: $95^{\circ} \mathrm{C}, 2 \mathrm{~min}$ followed by $40 \mathrm{cy}$ cles of $95{ }^{\circ} \mathrm{C}, 10 \mathrm{sec}$ and $60{ }^{\circ} \mathrm{C}, 45 \mathrm{sec}$. The PCR was run in duplicates using a relative standard curve approach. The standard curve was generated by performing serial dilutions of plasmid DNA containing one copy of the area of interest for each of the assayed genes. pUC57 plasmid DNA (GenScript, Piscataway, NJ,USA) was added to each standard to maintain a constant amount of total DNA per reaction tube. Only $\mathrm{R}^{2}$ values above 0.99 were accepted and data was quality controlled in accordance with previous recommendations [23]. For confirmation, analysis of $>5 \%$ of all samples was repeated. Control DNA isolated from cancer-free individuals was used to normalize for plate variability. Copy numbers below 1.5 and above 2.5 were defined as deleted and amplified, respectively.

\section{Analysis of frequency of TP53 mutations and PAH-DNA adduct levels}

To assess the frequency of TP53 mutations in tumor tissues DNA was screened either by single-strand conformational polymorphism or denaturating capillary electrophoresis as previously described, covering exons 4 to 9 of the TP53 gene, and DNA samples with alterations were sequenced $[25,26]$. PAH-DNA adduct levels were determined in non-tumorous lung tissue by ${ }^{32} \mathrm{P}$-postlabelling as previously published [27]. The patients were divided into two groups on the basis of having levels greater than or less than the median (9.91) of DNA adducts per $10^{8}$ nucleotides.

\section{Cell culture and RNA knockdown}

Lung adenocarcinoma A427 cells were maintained in RPMI-1640 medium (Thermo Scientific) with $10 \%$ FCS (Thermo Scientific), and penicillin/streptomycin (Biowest SAS, Nuaillé, France) in $5 \% \mathrm{CO}_{2}$ at $37{ }^{\circ} \mathrm{C}$. The cells were passaged every third day and passage numbers between 25 and 30 were used in all experiments. In RNA knockdown experiments 100000 cells $/ \mathrm{mL}$ were seeded in $2 \mathrm{~mL}$ growth medium without penicillin/streptomycin in 6-well plates. For protein isolation 200000 cells $/ \mathrm{mL}$ were seeded in $10 \mathrm{~mL}$ medium without penicillin/streptomycin in $10 \mathrm{~cm}^{2}$ plates. siRNA targeting human TP53, SOX2 and nontarget (control) were purchased from Applied Biosystems (Thermo Scientific). Transfections were performed $24 \mathrm{~h}$ after seeding using $10 \mathrm{nM}$ siRNA and Lipofectamin RNAiMAX reagent (Invitrogen, Thermo Scientific) according to manufacturer's instructions. The cells were harvested $48 \mathrm{~h}$ after transfection to analyze RNA, miRNA and protein expression.

\section{Western blotting}

Nuclear proteins were extracted from knockdown and control A427 cells using NE-PER Nuclear and Cytoplasmic extraction reagents (Thermo Scientific, Rockford, IL, USA). Protein concentrations were determined by BCA Protein Assay (Thermo Scientific) and $40 \mu \mathrm{g}$ lysate was separated by $10 \%$ SDS-PAGE and transfer to a Immobilon PVDF membrane (Millipore, Bedford, MA, USA). To prevent non-specific background binding, the membranes were incubated with $5 \%$ non-fat milk in Tris-buffered saline with $0.05 \%$ Tween-20 (TBST) for $1 \mathrm{~h}$ at room temperature. Membranes were incubated with primary antibodies against SOX2 and TP53 (Cell Signaling technology Inc., Beverly, MA, USA) over night at $4{ }^{\circ} \mathrm{C}$ and against GAPDH (Santa Cruz Biotechnology, Santa Cruz, CA, USA) for $1 \mathrm{~h}$ at room temperature. After washing three times with TBST, the membranes were incubated with secondary anti-rabbit antibody (Cell Signaling) for $1 \mathrm{~h}$ at room temperature and proteins visualized by SuperSignal West Pico Chemiluminescent Substrate (Thermo Scientific). Semiquantitative densitometry analysis were performed using Image J.

\section{Gene expression analysis}

Total RNA was isolated from frozen lung tissue samples using standard Trizol extraction and total RNA from transfected cells was isolated using NucleoSpin miRNA (Macherey-Nagel, Duren, Germany). RNA was DNase treated with DNA-free kit (Ambion, Thermo Scientific) and its quality was assessed by 2100 Bioanalyzer (Agilent Technologies, Santa Clara, CA, USA). For gene expression analysis total RNA was reversed transcribed using qScript cDNA Supermix or qScript cDNA synthesis kit (Quanta BioSciences) for tissue samples and cells respectively. 
Beta-Actin $(A C T B)$ was used as reference gene. Primer sequences were: SOX2 forward primer, 5'-GGGGAAAGTAGTTTGCTGCC-3', reverse primer, 5'-CGCCGCCGA TGATTGTTATT-3', TP53 forward primer, 5'-CCATCCT CACCATCATCACA-3, reverse primer, 5'CACAAAC ACGCACCTCAAAG-3', ACTB forward primer, 5'-GCG AGAAGATGACCCAGATCA-3', reverse primer, 5'-GATA GCACAGCCTGGATAGCAA-3'. TargetScan 6.2 (http:// www.targetscan.org/) was used to predict conserved miRNA binding sites in the SOX2 gene. Of these five previously known targets of TP53; hsa-miR-145-5p, hsa-miR145-3p, hsa-miR-200b-3p, hsa-miR-200c-3p, hsa-miR429-1p; were selected for further analysis. Accordingly, total RNA was reversed transcribed using qScript microRNA cDNA Synthesis Kit (Quanta BioSciences) and expression was analyzed using commercial primers (Integrated DNA Technologies, Leuven, Belgium). SNO and RNU6 were used as references. Expression was evaluated by qPCR using SYBR Green I technology on an ABI PRISM $^{\circ} 7900$ HT Fast Real-Time PCR System (Applied Biosystems, Thermo Scientific). Primer specificity was determined by melting point analysis.

\section{Statistical analysis}

Statistical analyses were carried out using IBM SPSS software version 22.0. Associations between copy number variation and lung cancer were estimated by odds ratios (ORs) and their $95 \%$ confidence intervals (CIs) from conditional logistic regression adjusted for age, gender, total pack-years and tumor histology. The total number of patients included in the study was 258 . However, for some patients, data on smoking status, gender or age was missing, and for five patients CNV data was not successfully obtained, thus giving a reduced number of patients included in the final statistical analysis. Effects of clinicopathological data on gene status were assessed by Chi-square or Fisher's exact test for categorical variables and by nonparametric tests for ordinal variables. Cancer free survival was obtained from 241 patients by Kaplan Meier analysis. Expression data was analyzed using nonparametric Mann-Whitney test or one-way ANOVA. $p<0.05$ was considered significant.

\section{Results}

\section{SOX2 copy number alterations are frequent in NSCLC} tumors

Analyses of gene copy numbers were performed on DNA from paired non-tumorous and tumor tissue of the same patient in order to evaluate whether genomic variations in SOX2 may be associated with lung tumor development. The SOX2 copy number alterations were more frequent in tumors than in non-tumorous tissues of NSCLC patients (Fig. 1a). The odds for acquiring a copy alteration in SOX2 were 12.6-fold higher (95\% CI: 5.8-27.1) in tumors than in non-tumorous tissues. SOX2 gene amplifications were observed in $33.6 \%$ of tumors compared with $3.2 \%$ in the adjacent non-tumorous tissues (OR: 15.7, 95 \% CI: 6.3-39.1, $p<0.001$ ). A low occurrence of SOX2 gene deletions was also observed in $6.1 \%$ of tumors (OR: 6.0, $95 \%$ CI: 1.6-23.0, $p=0.009$ ). Amplifications of $>5$ copies were observed in 15 of 81 tumors with a SOX2 amplification (Fig. 1b), and SOX2 copy number alterations were most frequent in squamous cell carcinoma (Fig. 1c). Moreover, changes in SOX2 gene status were more frequent in smokers than non-smokers $(p=0.015$, Additional file 1: Table S1). SOX2 mRNA expression levels were investigated in 15 tumor and 15 non-tumorous tissue samples, and a strong correlation, $(r=0.875, p=0.001)$, was observed between the SOX2 copy numbers and the relative SOX2 mRNA expression level (Fig. 1d). SOX2 copy number alterations did not affect the survival of the patients (data not shown).

\section{Mutations in TP53 gene increase frequency of SOX2 copy number alterations}

The effects of TP53 mutations on SOX2 copy number were investigated in 229 tumor tissues of the NSCLC patients. Of these, $56.8 \%$ had at least one mutation in their lung tumors. Patients with mutated TP53 had a significantly higher odds of acquiring a copy number variation in SOX2 (OR $=2.08,95 \%$ CI: $1.14-3.79, p=0.017)$ than patients without TP53 mutations (Fig. 2a). Furthermore, a positive correlation $(r=0.447, p=0.013)$ was observed between TP53 and SOX2 mRNA expression levels in a subset of cancer patients ( $n=30$, Fig. $2 b)$. TP53 mutations are often occurring as a consequence of DNA-adduct formation following exposure to genotoxic carcinogens such as PAHs in cigarette smoke. However, increased PAHadduct levels did not increase the occurrence of SOX2 copy number alterations in our material (data not shown), despite a higher frequency of $S O X 2$ gene alterations in smokers compared to the non-smoking NSCLC patients.

\section{TP53 affects SOX2 expression and hsa-miRNA-145-5p levels in human lung cells in vitro}

To investigate the effect of TP53 on SOX2 expression in NSCLC, the TP53 gene was silenced in the lung adenocarcinoma A427 cell line using siRNA. Effective knockdown of TP53 and SOX 2 proteins after $48 \mathrm{~h}$ was confirmed in three independent experiments by western blotting (Fig. 3a). In TP53 knockdown cells a significant $40 \%$ reduction in SOX2 mRNA and protein expression was observed ( $p=0.001$, Fig. $4 \mathrm{a}$ and $p=0.01$, Fig. 3b). SOX2 knockdown did not affect the expression of TP53 (Fig. 4b). Moreover, hsa-miR-145-5p expression 

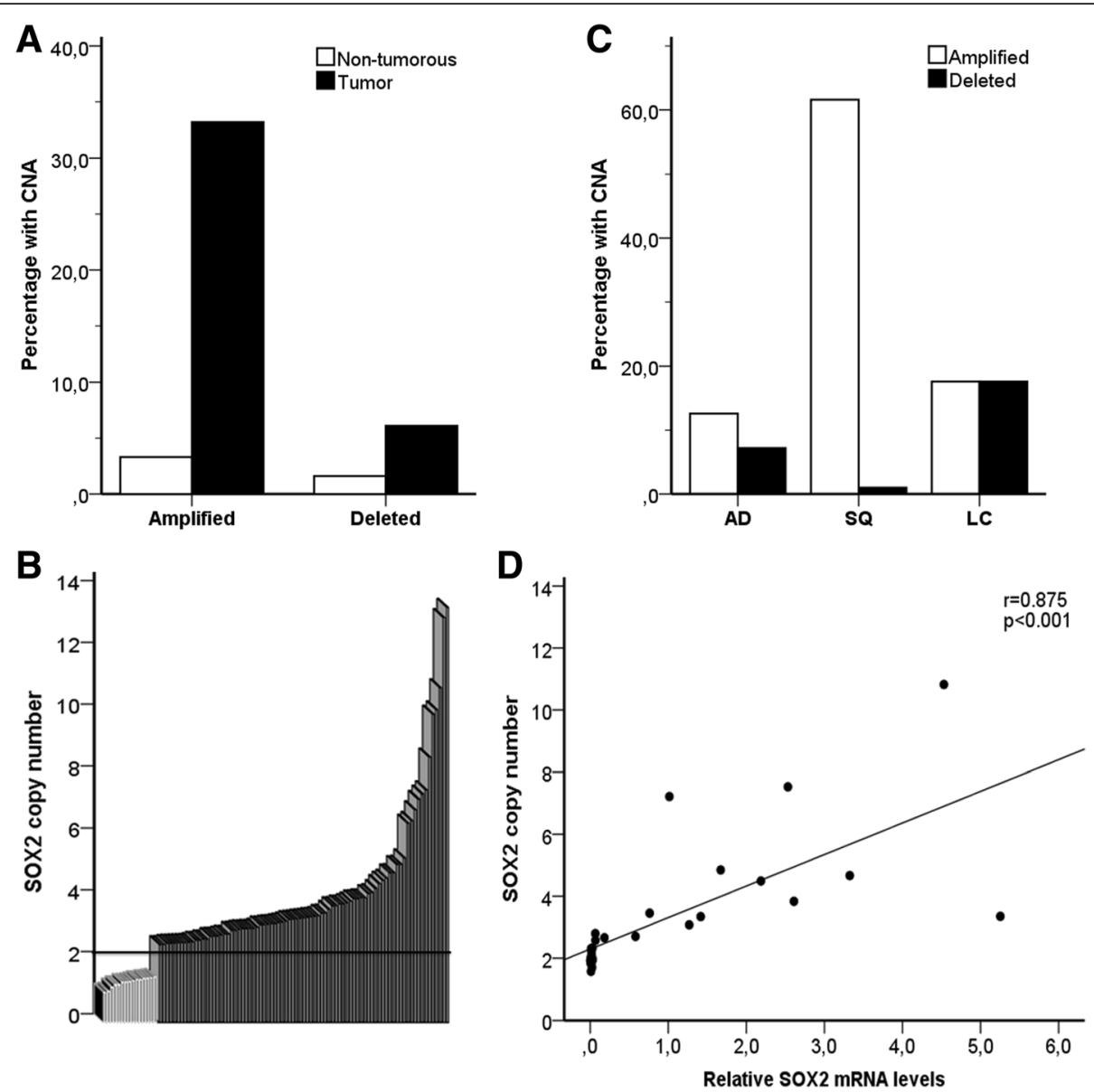

Fig. 1 SOX2 copy number alterations in lung tumors $(n=244)$. a Percentage of SOX2 gene amplifications and deletions in lung tumors and non-tumorous tissues. b Distribution of SOX2 copy numbers in lung tumors. More than 2.5 copy numbers were defined as amplifications, whereas less than 1.5 copy numbers were defined as deletions. c Distribution of copy number alterations between NSCLC of different histology. AD: adenocarcinoma, SQ: squamous cell carcinoma and LC: large cell carcinoma. d Correlation between the relative genomic SOX2 levels and its mRNA expression. $r=0.875, p<0.001$ was obtained from Spearman's Rank-Order Correlation $(n=30)$
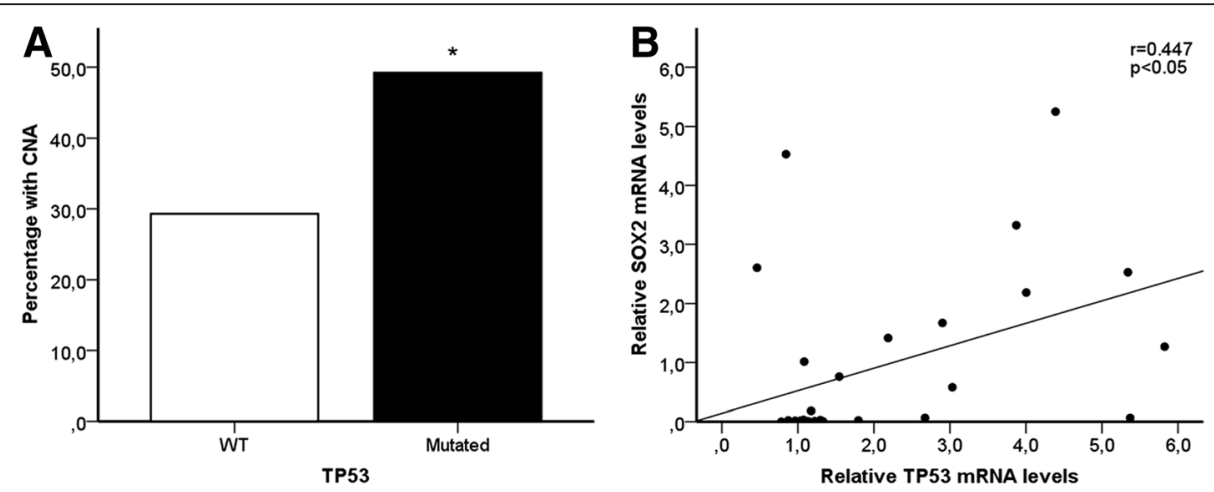

Fig. 2 a TP53 gene status in tumor tissue of patients and its association with copy number alterations (CNA) in the SOX2 gene. ${ }^{* *} p=0.017$, was obtained from unconditional logistic regression, adjusted for age, gender, total pack-years and histology $(n=229)$. $\mathbf{b}$ Correlation between the relative SOX2 and TP53 mRNA expression. $r=0.447, p=0.013$ was obtained from Spearman's Rank-Order Correlation $(n=30)$ 


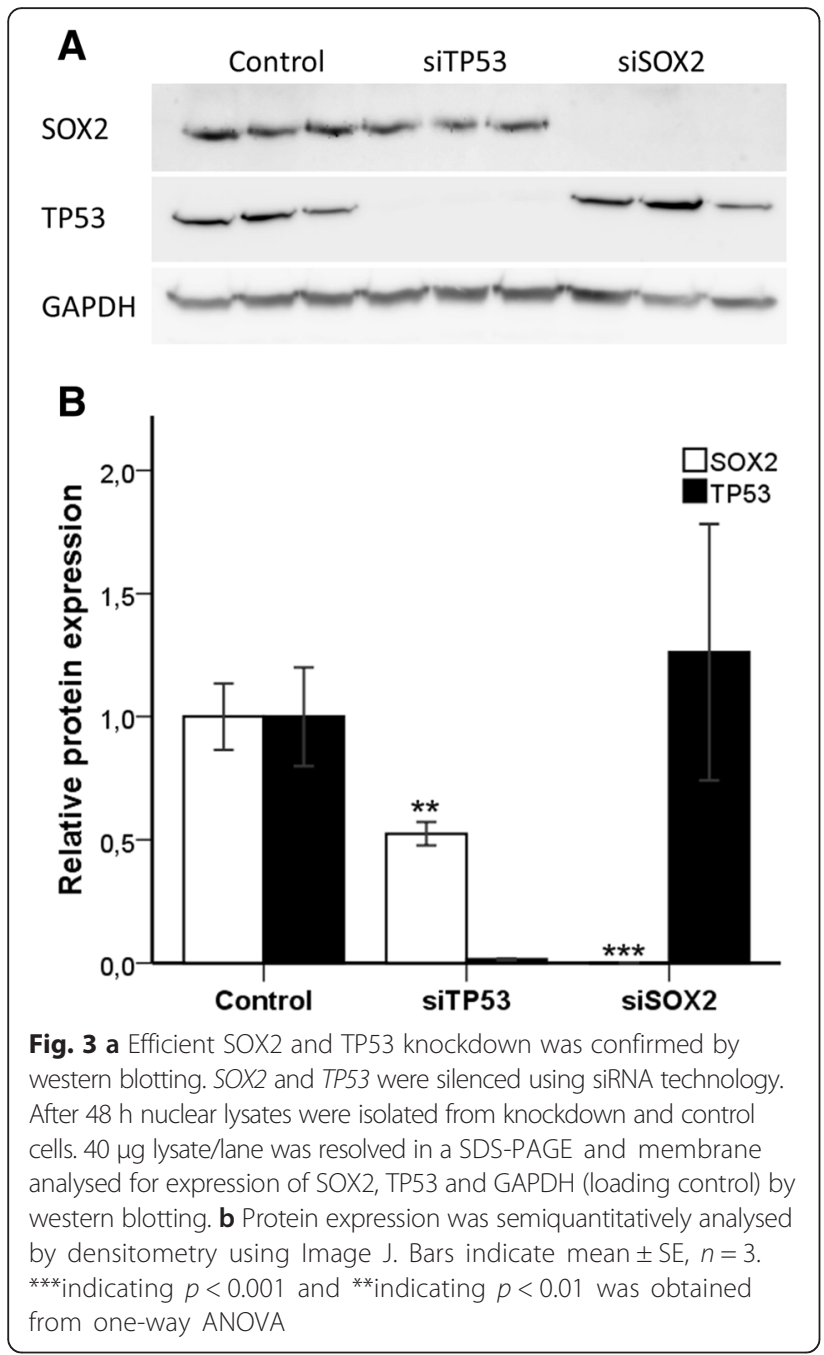

Fig. 3 a Efficient SOX2 and TP53 knockdown was confirmed by western blotting. SOX2 and TP53 were silenced using siRNA technology. After $48 \mathrm{~h}$ nuclear lysates were isolated from knockdown and control cells. $40 \mathrm{\mu g}$ lysate/lane was resolved in a SDS-PAGE and membrane by densitometry using Image $J$. Bars indicate mean \pm SE, $n=3$. ***indicating $p<0.001$ and ${ }^{*}$ indicating $p<0.01$ was obtained from one-way ANOVA was significantly reduced in TP53 knockdown cells ( $p=$ 0.004, Fig. 4a). In contrast, the levels of hsa-miR-145-3p, hsa-miR-200b and hsa-miR-200c remained unchanged in TP53 knockdown cells, whereas hsa-miR-429 was not expressed in these cells (data not shown).

\section{Discussion}

SOX2 has a crucial role in maintaining the stem cell-like phenotype in cancer cells $[12,13]$ and its overexpression is generally associated with aggressive disease and poor outcome in several different tumor types [28-32]. SOX2 has been identified as the driving gene of the 3q25-27 amplicon, which is common in most NSCLC cases and contributes to the pathogenesis of lung cancer by controlling cell proliferation and malignant transformation [11]. Comparison of tumor tissue with non-tumorous tissue obtained from the same patients confirmed that tumor tissues had significantly higher odds of acquiring a copy number alteration in the SOX2 gene. Surprisingly, SOX2 copy number deletions were detected in a subset of tumor samples in this cohort. Deletions in SOX2 copy number have not previously been reported in NSCLC and the importance of this finding remains to be elucidated. SOX2 gene amplifications were observed in $34 \%$ of tumors in this study. SOX2 has been shown to be highly expressed in approximately $90 \%$ of pulmonary squamous cell carcinoma and to a lesser extent in adenocarcinoma [16] and several studies have previously identified SOX2 gene amplifications in lung squamous cell carcinomas with reported frequencies from $20 \%$ to $60 \%[13,15,33-36]$. Here, we observed higher frequency of SOX2 copy number amplifications in squamous cell carcinoma tumors (59\%) than in adeno- (20\%) or large cell carcinoma (34\%). These data are in line with previous reports indicating a role for SOX2 in carcinogenesis. Accordingly, SOX2 affects tumorigenesis and its overexpression increases cell
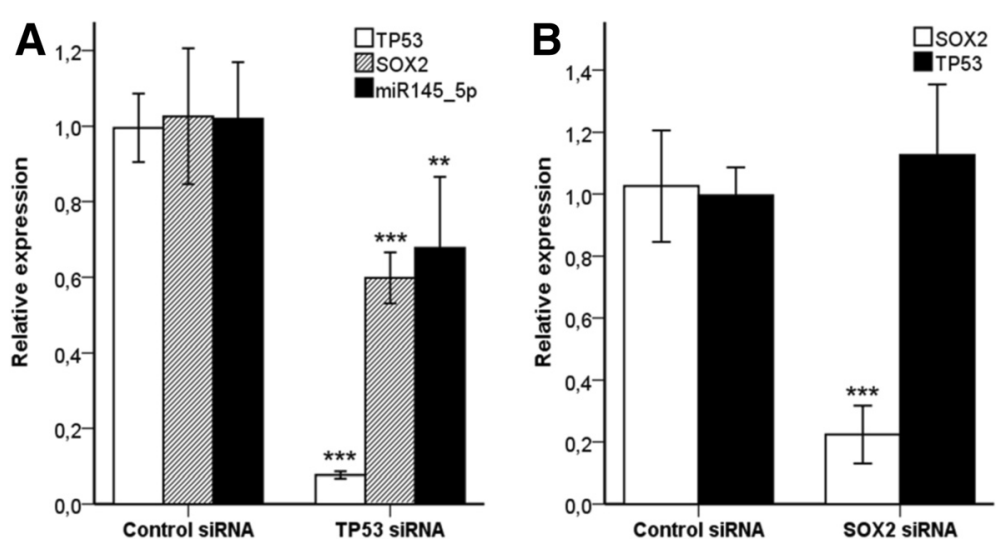

Fig. 4 Effects of silencing of the TP53 and SOX2 genes on the expression of SOX2, TP53 and hsa-miRNA-145-5p in pulmonary adenocarcinoma A427 cells. a TP53 was silenced using siRNA technology and expression of SOX2 and hsa-miR-145-5p was analyzed by qPCR. Bars indicate mean \pm SE, $n=9$ and $n=12$ for SOX2 and hsa-miR-145-5p, respectively. b SOX2 was silenced using siRNA technology and expression of TP53 was analyzed by qPCR. Bars indicate mean $\pm \mathrm{SE}, n=9$. ${ }^{* *}$ indicating $p<0.001$ and ${ }^{* *}$ indicating $p<0.01$ was obtained from nonparametric Mann-Whitney test 
migration and colony formation, while its knockdown impairs cell growth and suppresses metastasis of lung cancer cells [35, 37-39]. Increased SOX2 expression is associated with metastatic progression [40] and SOX2 gene amplifications are more frequent in highgrade than low-grade lesions [41]. Moreover, conditional homozygous overexpression of SOX2 in murine Clara cells induces bronchial epithelial hyperplasia with progression to lung cancer in approximately $50 \%$ of the animals [42]. Taken together, these results support the hypothesis that SOX2 may act as an oncogene in lung carcinogenesis.

The prognostic role of SOX2 in NSCLC remains uncertain as conflicting data has been reported. SOX2 amplifications and overexpression have been reported as predictors of prolonged survival in squamous cell carcinomas $[15,43]$. On contrary, SOX2 expression is suggested a poor prognosis predictor in stage I lung adenocarcinoma [44]. Wilbertz et al. investigated SOX2 amplifications and expression in two cohorts and reported no association between SOX2 expression and survival in lung adenocarcinoma; however, observed a decreased survival in patients with low-level amplifications in one of the cohorts [15]. Differences in biological properties of tumorinitiating cancer stem cells in squamous cell carcinoma compared to lung or breast adenocarcinoma have been suggested as an explanation to the different observed associations between SOX2 gene amplifications and prognosis [45]. Recently, several studies have showed improved outcome as a consequence of $S O X 2$ gene amplification in NSCLC, independent of histological subtype [14, 46, 47]. In our study, no significant effect on survival rates could be demonstrated, but this may be due to limited number of patients investigated. Moreover, differences in patient clinical characteristcs, methodology and scoring criteria might explain some of the reported discrepancies. Clearly, more studies are needed to elucidate the role of SOX2 in lung cancer progression and prognosis.

TP53 has been demonstrated to down-regulate several stem cell-associated genes, including SOX2, following DNA damage in embryonic stem cells [17]. Moreover, a recent report indicated that induction of TP53 led to repressed SOX2 expression in NSCLC cells [18]. Since genetic alterations in the TP53 gene are significant events in lung cancers [6], and mutations in the TP53 gene increase the risk for chromosomal rearrangements such as copy number alterations [8], these early reports open up the possibility of TP53 as an important regulator of SOX2 in NSCLC. To address this, the effects of TP53 mutational status on SOX2 copy number and expression levels were studied in NSCLC patients. Interestingly, patients with at least one mutation in their lung tumors possessed a 2-fold higher risk of having a copy number variation in SOX2. This is to our knowledge the first study to report an association between TP53 mutations and SOX2 copy number alterations. However, individuals carrying TP53 mutations show generally higher levels of germline copy number variation [48]. Furthermore, smoking is known to increase the risk of acquiring TP53 mutations [49-51] and, similarly, we and others [34, 36] have demonstrated that smokers have a higher risk of acquiring SOX2 copy number alterations in tumors. Hence, TP53 mutations may contribute to SOX2 copy number alterations in lung cancer patients. Moreover, a correlation between TP53 and SOX2 expression levels was observed in NSCLC tumors. To further investigate this relationship, silencing of TP53 and $S O X 2$ was performed in the lung adenocarcinoma cell line A427. TP53 knockdown reduced SOX2 mRNA and protein expression, whereas $S O X 2$ knockdown did not affect TP53 expression levels, indicating a regulatory role of TP53 on SOX2 in NSCLC. Considering the role of SOX2 in tumorigenesis it could be expected that TP53 knockdown would increase SOX2 expression. Indeed, Chen et al. have previously shown a reduction in SOX2 expression following TP53 induction in the TP53null NSCLC cell line H1299 [18]. These discrepancies as well as reports on conflicting effects on NSCLC prognosis following SOX2 copy number amplification indicate that the role of SOX2 in NSCLC is far more complex than can be explained by histology or TP53 status only.

There is a need to further investigate the mechanisms of TP53 regulation of SOX2. To address this, the possible involvement of miRNAs was investigated. This is of interest as a more prominent role of miRNAs in cancer development has emerged during recent years and TP53 regulates the expression of several genes through miRNAs $[52,53]$. Hsa-miR-145 is an interesting candidate as TP53 activates expression of hsa-miR-145 which in turn represses SOX2 expression in embryonic stem cells [19-21]. Hsa-miR-145 expression has also been suggested as a novel marker responsible for relapse in surgically treated NSCLC [22]. Campayo et al. demonstrated that TP53 may play a role in modulating hsa-miR-145 expression in NSCLC, and that patients with mutations in TP53 and low hsa-miR-145 levels had lower survival in respect to patients with TP53 wild-type or only mutations in TP53 [22]. We here demonstrated that TP53 knockdown repressed hsa-miR-145-5p expression in the lung adenocarcinoma cell line A427, whereas the other miRNAs investigated were unaffected. miRNAs have previously been believed to affect gene expression modulation only by negative regulation of target mRNA. Increasing evidence now indicate that miRNAs oscillate between repression and induction of gene expression in response to specific cellular conditions and cofactors [54]. Based on our findings, we suggest a possible role of hsa-miR-145 as an inducer of SOX2 expression in NSCLC. It is known that hsa-miR- 
145 exhibits opposite effects on RNA regulation in different cell types. Indeed, hsa-miR-145 mediates gene upregulation during muscle differentiation [55] and gene downregulation in osteosarcoma [56]. Other approaches to further investigate the possible regulation of TP53 on SOX2 in several different lung cancer cell lines and in different cellular states are clearly needed, as well as additional studies to fully understand the complexity of hsa-miR-145 signaling in lung cancer. Moreover, hsa-miR-638 has recently come into focus as another promising candidate, as it has been shown that hsa-miR-638 regulates SOX2 in NSCLC [57]. Interestingly, hsa-miR-638 is known as a TP53-targeting miRNA [58], further illustrating the complexity of this signaling.

\section{Conclusions}

TP53 mutations were associated with an increased risk of acquiring a SOX2 copy number amplification in NSCLC. Furthermore, SOX2 and TP53 expression were correlated in lung tumors and reduction in TP53 resulted in decreased SOX2 and hsa-miR-145 expression in lung adenocarcinoma cells. As hsa-miR-145 has previously been shown to regulate SOX2 expression, we propose that one mechanism for the TP53 regulation of SOX2 may be through hsa-miR-145. This prompts for further studies on the mechanisms behind TP53-induced regulation of SOX2 expression and the possible importance of hsamiR-145 in lung cancer development.

\section{Additional file}

Additional file 1: Table S1. Association between clinicopathological data and SOX2 gene status in NSCLC tumors. (PDF $101 \mathrm{~kb}$ )

\section{Abbreviations}

NSCLC: Non-small cell lung cancer; OR: Odds ratio; PAH: Polycyclic aromatic hydrocarbons.

\section{Competing interests}

All authors declare no conflict of interest.

\section{Authors' contributions}

JSE carried out molecular genetic studies, participated in statistical analysis and drafted the manuscript. VS coordinated the NSCLC databank and carried out the histopathology and survival analysis. PB and AG participated in the coordination of collection of healthy controls and commented the initial manuscript draft. AH participated in the design and coordination of the study and helped draft the manuscript. SZ led the study, was involved in TP53 mutational analysis, participated in its design and helped draft the manuscript. All authors read and approved the final manuscript.

\section{Acknowledgments}

Professor Lodve B. Stangeland (University of Bergen, Norway), Professor David H. Phillips (King's College, London) and Dr. Steen Mollerup are acknowledged for their kind contribution in collecting tissue samples, preparing tissues and analyzing PAH-DNA adducts, respectively. We also thank Dr. Vegard Eldholm for his support on primer design. Tove Andreassen and Elin Thorner Einarsdottir are acknowledged for excellent technical assistance. This study was supported by the Norwegian Cancer Society.

\section{Author details}

1Department of Biological and Chemical Work Environment, National Institute of Occupational Health, PO Box 8149 Dep, N-0033 Oslo, Norway.

${ }^{2}$ Department of Clinical Science, University of Bergen, Bergen, Norway.

Received: 28 April 2015 Accepted: 10 January 2016

Published online: 19 January 2016

\section{References}

1. Jemal A, Bray F, Center MM, Ferlay J, Ward E, Forman D. Global cancer statistics. CA Cancer J Clin. 2011;61:69-90.

2. Staaf J, Isaksson S, Karlsson A, Jonsson M, Johansson L, Jonsson P, et al. Landscape of somatic allelic imbalances and copy number alterations in human lung carcinoma. Int J Cancer. 2013;132:2020-31.

3. Seo JS, Ju YS, Lee WC, Shin JY, Lee JK, Bleazard T, et al. The transcriptional landscape and mutational profile of lung adenocarcinoma. Genome Res. 2012;22:2109-19.

4. Iwakawa R, Takenaka M, Kohno T, Shimada Y, Totoki Y, Shibata T, Tsuta K, Nishikawa R, Noguchi M, Sato-Otsubo A et al. Genome-wide identification of genes with amplification and/or fusion in small cell lung cancer. Genes Chromosomes Cancer. 2013;52:802-16.

5. Cancer Genome Atlas Research Network. Comprehensive genomic characterization of squamous cell lung cancers. Nature. 2012;489:519-25.

6. Whibley C, Pharoah PD, Hollstein M. p53 polymorphisms: cancer implications. Nat Rev Cancer. 2009;9:95-107.

7. Henkler F, Stolpmann K, Luch A. Exposure to polycyclic aromatic hydrocarbons: bulky DNA adducts and cellular responses. EXS. 2012;101:107-31.

8. Llanos S, Efeyan A, Monsech J, Dominguez O, Serrano M. A High-Throughput Loss-of-Function Screening Identifies Novel p53 Regulators. Cell Cycle. 2006:5:1880-5.

9. Dillon LW, Burrow AA, Wang Y-H. DNA Instability at Chromosomal Fragile Sites in Cancer. Current Genomics. 2010;11:326-37.

10. Dehan E, Ben-Dor A, Liao W, Lipson D, Frimer H, Rienstein S, et al. Chromosomal aberrations and gene expression profiles in non-small cell lung cancer. Lung Cancer. 2007;56:175-84.

11. Balsara BR, Testa JR. Chromosomal imbalances in human lung cancer. Oncogene. 2002;21:6877-83.

12. Gontan C, de Munck A, Vermeij M, Grosveld F, Tibboel D, Rottier R. Sox2 is important for two crucial processes in lung development: branching morphogenesis and epithelial cell differentiation. Dev Biol. 2008;317:296-309.

13. Yuan P, Kadara H, Behrens C, Tang X, Woods D, Solis LM, et al. Sex determining region Y-Box 2 (SOX2) is a potential cell-lineage gene highly expressed in the pathogenesis of squamous cell carcinomas of the lung. PLoS One. 2010;5:e9112.

14. Velcheti V, Schalper K, Yao X, Cheng H, Kocoglu M, Dhodapkar K, et al. High SOX2 levels predict better outcome in non-small cell lung carcinomas. PLoS One. 2013;8:e61427.

15. Wilbertz T, Wagner P, Petersen K, Stiedl AC, Scheble VJ, Maier S, et al. SOX2 gene amplification and protein overexpression are associated with better outcome in squamous cell lung cancer. Mod Pathol. 2011;24:944-53.

16. Sholl LM, Long KB, Hornick JL. Sox2 expression in pulmonary non-small cell and neuroendocrine carcinomas. Appl Immunohistochem Mol Morphol. 2010;18:55-61

17. Li M, He Y, Dubois W, Wu X, Shi J, Huang J. Distinct regulatory mechanisms and functions for p53-activated and p53-repressed DNA damage response genes in embryonic stem cells. Mol Cell. 2012;46:30-42.

18. Chen K, Wu K, Cai S, Zhang W, Zhou J, Wang J, et al. Dachshund Binds p53 to Block the Growth of Lung Adenocarcinoma Cells. Cancer Res. 2013.

19. Jain AK, Allton K, lacovino M, Mahen E, Milczarek RJ, Zwaka TP, et al. p53 regulates cell cycle and microRNAs to promote differentiation of human embryonic stem cells. PLoS Biol. 2012;10:e1001268.

20. Avgeris M, Stravodimos K, Fragoulis EG, Scorilas A. The loss of the tumoursuppressor miR-145 results in the shorter disease-free survival of prostate cancer patients. Br J Cancer. 2013;108:2573-81.

21. Sachdeva M, Zhu S, Wu F, Wu H, Walia V, Kumar S, et al. p53 represses c-Myc through induction of the tumor suppressor miR-145. Proc Natl Acad Sci U S A. 2009;106:3207-12.

22. Campayo M, Navarro A, Vinolas N, Diaz T, Tejero R, Gimferrer JM, et al. Low miR-145 and high miR-367 are associated with unfavourable prognosis in resected nonsmall cell lung cancer. Eur Respir J. 2013;41:1172-8. 
23. D'Haene B, Vandesompele J, Hellemans J. Accurate and objective copy number profiling using real-time quantitative PCR. Methods. 2010;50:262-70.

24. Weaver S, Dube S, Mir A, Qin J, Sun G, Ramakrishnan R, et al. Taking qPCR to a higher level: Analysis of CNV reveals the power of high throughput qPCR to enhance quantitative resolution. Methods. 2010;50:271-6.

25. Lind $\mathrm{H}$, Ekstrom PO, Ryberg D, Skaug $V$, Andreassen $T$, Stangeland L, et al. Frequency of TP53 mutations in relation to Arg72Pro genotypes in non small cell lung cancer. Cancer Epidemiol Biomarkers Prev. 2007;16:2077-81.

26. Kristensen AT, Bjorheim J, Ekstrom PO. Detection of mutations in exon 8 of TP53 by temperature gradient 96-capillary array electrophoresis. Biotechniques. 2002;33:650-3.

27. Zienolddiny S, Skaug V, Landvik NE, Ryberg D, Phillips DH, Houlston R, et al. The TERT-CLPTM1L lung cancer susceptibility variant associates with higher DNA adduct formation in the lung. Carcinogenesis. 2009;30:1368-71.

28. Ge N, Lin HX, Xiao XS, Guo L, Xu HM, Wang X, et al. Prognostic significance of Oct4 and Sox2 expression in hypopharyngeal squamous cell carcinoma. J Transl Med. 2010:8:94.

29. Huang P, Qiu J, Li B, Hong J, Lu C, Wang L, et al. Role of Sox2 and Oct4 in predicting survival of hepatocellular carcinoma patients after hepatectomy. Clin Biochem. 2011:44:582-9.

30. Matsuoka J, Yashiro M, Sakurai K, Kubo N, Tanaka H, Muguruma K, et al. Role of the stemness factors sox 2 , oct $3 / 4$, and nanog in gastric carcinoma. J Surg Res. 2012;174:130-5.

31. Saigusa S, Mohri Y, Ohi M, Toiyama Y, Ishino Y, Okugawa Y, et al. Podoplanin and SOX2 expression in esophageal squamous cell carcinoma after neoadjuvant chemo-radiotherapy. Oncol Rep. 2011;26:1069-74.

32. Wang X, Liang Y, Chen Q, Xu HM, Ge N, Luo RZ, et al. Prognostic significance of SOX2 expression in nasopharyngeal carcinoma. Cancer Invest. 2012;30:79-85.

33. Bass AJ, Watanabe H, Mermel CH, Yu S, Perner S, Verhaak RG, et al. SOX2 is an amplified lineage-survival oncogene in lung and esophageal squamous cell carcinomas. Nat Genet. 2009:41:1238-42.

34. Cai YR, Zhang HQ, Zhang ZD, Mu J, Li ZH. Detection of MET and SOX2 amplification by quantitative real-time PCR in non-small cell lung carcinoma. Oncol Lett. 2011;2:257-64.

35. Hussenet T, Dali S, Exinger J, Monga B, Jost B, Dembele D, et al. SOX2 is an oncogene activated by recurrent 3q26.3 amplifications in human lung squamous cell carcinomas. PLoS One. 2010:5:e8960.

36. Sasaki H, Yokota K, Hikosaka Y, Moriyama S, Yano M, Fujii Y. Increased Sox2 copy number in lung squamous cell carcinomas. Exp Ther Med. 2012:3:44-8.

37. Nakatsugawa M, Takahashi A, Hirohashi Y, Torigoe T, Inoda S, Murase M, et al. SOX2 is overexpressed in stem-like cells of human lung adenocarcinoma and augments the tumorigenicity. Lab Invest. 2011;91:1796-804.

38. Chen S, Xu Y, Chen Y, Li X, Mou W, Wang L, et al. SOX2 gene regulates the transcriptional network of oncogenes and affects tumorigenesis of human lung cancer cells. PLoS One. 2012;7:e36326.

39. Xiang R, Liao D, Cheng T, Zhou H, Shi Q, Chuang TS, et al. Downregulation of transcription factor SOX2 in cancer stem cells suppresses growth and metastasis of lung cancer. Br J Cancer. 2011;104:1410-7.

40. Singh S, Trevino J, Bora-Singhal N, Coppola D, Haura E, Altiok S, et al. EGFR/ Src/Akt signaling modulates Sox2 expression and self-renewal of stem-like side-population cells in non-small cell lung cancer. Mol Cancer. 2012;11:73.

41. McCaughan F, Pole JC, Bankier AT, Konfortov BA, Carroll B, Falzon M, et al. Progressive $3 \mathrm{q}$ amplification consistently targets $\mathrm{SOX} 2$ in preinvasive squamous lung cancer. Am J Respir Crit Care Med. 2010;182:83-91.

42. Lu Y, Futtner C, Rock JR, Xu X, Whitworth W, Hogan BL, et al. Evidence that SOX2 overexpression is oncogenic in the lung. PLoS One. 2010;5:e11022.

43. Brcic L, Sherer CK, Shuai Y, Hornick JL, Chirieac LR, Dacic S. Morphologic and Clinicopathologic Features of Lung Squamous Cell Carcinomas Expressing Sox2. Am J Clin Pathol. 2012;138:712-8.

44. Sholl LM, Barletta JA, Yeap BY, Chirieac LR, Hornick JL. Sox2 protein expression is an independent poor prognostic indicator in stage I lung adenocarcinoma. Am J Surg Pathol. 2010;34:1193-8.

45. Hussenet T, du Manoir S. SOX2 in squamous cell carcinoma: amplifying a pleiotropic oncogene along carcinogenesis. Cell Cycle. 2010;9:1480-6.

46. Toschi L, Finocchiaro G, Nguyen TT, Skokan MC, Giordano L, Gianoncelli L, et al. Increased SOX2 Gene Copy Number Is Associated with FGFR1 and PIK3CA Gene Gain in Non-Small Cell Lung Cancer and Predicts Improved Survival in Early Stage Disease. PLoS One. 2014;9:e95303.
47. Chen Y, Huang Y, Huang Y, Chen J, Wang S, Zhou J. The prognostic value of SOX2 expression in non-small cell lung cancer: a meta-analysis. PLoS One. 2013;8:e71140.

48. Shlien A, Tabori U, Marshall CR, Pienkowska M, Feuk L, Novokmet A, et al. Excessive genomic DNA copy number variation in the Li-Fraumeni cancer predisposition syndrome. Proc Natl Acad Sci U S A. 2008;105:11264-9.

49. Husgafvel-Pursiainen K, Boffetta P, Kannio A, Nyberg F, Pershagen G, Mukeria A, et al. p53 mutations and exposure to environmental tobacco smoke in a multicenter study on lung cancer. Cancer Res. 2000;60:2906-11.

50. Takagi Y, Osada H, Kuroishi T, Mitsudomi T, Kondo M, Niimi T, et al. p53 mutations in non-small-cell lung cancers occurring in individuals without a past history of active smoking. Br J Cancer. 1998;77:1568-72.

51. Vahakangas KH, Bennett WP, Castren K, Welsh JA, Khan MA, Blomeke B, et al. p53 and K-ras mutations in lung cancers from former and never-smoking women. Cancer Res. 2001;61:4350-6.

52. MacNeil AJ, Jiao S-C, McEachern LA, Yang YJ, Dennis A, Yu H, et al. MAPK Kinase 3 Is a Tumor Suppressor with Reduced Copy Number in Breast Cancer. Cancer Res. 2014;74:162-72.

53. Fischer U, Heckel D, Michel A, Janka M, Hulsebos T, Meese E. Cloning of a Novel Transcription Factor-Like Gene Amplified in Human Glioma Including Astrocytoma Grade I. Hum Mol Genet. 1997;6:1817-22.

54. Valinezhad Orang A, Safaralizadeh R, Kazemzadeh-Bavili M. Mechanisms of miRNA-Mediated Gene Regulation from Common Downregulation to mRNA-Specific Upregulation. Int J Genomics. 2014:2014:970607.

55. Cordes KR, Sheehy NT, White M, Berry E, Morton SU, Muth AN, et al. miR-145 and miR-143 Regulate Smooth Muscle Cell Fate Decisions. Nature. 2009;460:705-10.

56. Li E, Zhang J, Yuan T, Ma B. miR-145 inhibits osteosarcoma cells proliferation and invasion by targeting ROCK1. Tumor Biology. 2014;35:7645-50.

57. Park JH, Roeder RG. GAS41 is required for repression of the p53 tumor suppressor pathway during normal cellular proliferation. Mol Cell Biol. 2006;26:4006-16.

58. Han J, Sun P. The pathways to tumor suppression via route p38. Trends Biochem Sci. 2007;32:364-71

\section{Submit your next manuscript to BioMed Central and we will help you at every step:}

- We accept pre-submission inquiries

- Our selector tool helps you to find the most relevant journal

- We provide round the clock customer support

- Convenient online submission

- Thorough peer review

- Inclusion in PubMed and all major indexing services

- Maximum visibility for your research

Submit your manuscript at www.biomedcentral.com/submit 